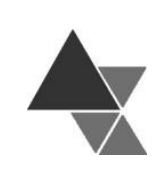

\title{
Comida e aspectos simbólicos na perspectiva de políticas públicas para o cumprimento do Direito Humano à Alimentação Adequada e
} Saudável

\author{
Anelise Rizzolo de Oliveira ${ }^{1}$
}

O Direito Humano à Alimentação Adequada e Saudável (DHAAS) é uma das garantias fundamentais de cidadania. Promover a Segurança Alimentar e Nutricional é responsabilidade do Estado mediante politicas públicas para a realização do DHAAS. Este ensaio se propõe a resgatar o processo de construção e significação do conceito de alimentação saudável e adequada (AAS) na formulação de políticas públicas, evidenciando as contradições e destacando a comida e seus aspectos simbólicos. A AAS é a realização de um direito humano, com a garantia ao acesso permanente e regular, socialmente justo, adequada aos aspectos biologicos e sociais dos individuos, as dimensoes de genero e etnia, e a produção ambientalmente sustentavel, livre de contaminantes fisicos, quimicos, biologicos, de organismos geneticamente modificado e pautada no referencial cultural dos povos e comunidades. A alimentaçao e a comida são categorias politicamente imbricadas, mas socialmente distintas. A inserção da comida e do simbólico nos processos de implementação das políticas e programas de SAN, parece ter evidenciado a importância da origem e da identidade cultural das comidas para o cumprimento do DHAAS. É fundamental continuar construindo um debate epistemológico que incorpore a premissa interdisciplinar, complexa, interseccional e intercultural da alimentação com os campos do saber que a configuram.

Palavras-chave: Comida; simbólico; cultura; Direito Humano à Alimentação; políticas públicas.

\section{Symbolic aspects of food to contribute to Public Policies Human Right to Adequate and Health Food}

The Human Right to Adequate and Health Food (HRAHF) is one of the fundamental guarantees of the citzenship. Promoting Food and Nutritional Security is a State responsibility through public policies capable of ensuring the achievement of HRAHF. This essay proposes to rescue the process of construction and significance of the concept of Adequate and Health Food (AHF) in the formulation of public policies. The AHF is the guarantee to the permanent and regular access, in a socially just way, to a proper food practice to the biological and social aspects, the dimensions of gender and ethnicity, and the forms of production environmentally sustainable, free of physical, chemical, biological contaminants, genetically modified organisms and based on the cultural reference of peoples and communities. Food have two approaches interwoven: political and social, two distinct categories. The insertion

${ }_{1}^{1}$ Professora Associada. Departamento de Nutrição. Faculdade de Ciências da Saúde. Universidade de Brasília. Campus Universitário Darci Ribeiro. Brasilia - DF. CEP: 70000-000. https://orcid.org/0000-0002-4683-8736.E-mail: anelise.unb@gmail.com 
of food and symbolic in the implementation processes of SAN policies and programs, seems to have highlighted the importance of the origin and cultural identity of foods for the fulfillment of HRAHF. It is essential to continue building an epistemological debate that incorporates the interdisciplinary, complex, intersectional and intercultural premise of food with the fields of knowledge that configure it.

Keywords: Food; symbolic; culture; Human Right to Adequate and Health Food; public policy.

O Direito Humano à Alimentação Adequada e Saudável (DHAAS) tornou-se uma das garantias fundamentais do cidadão brasileiro na Constituição Federal, após mais de uma década de tensões políticas entre Estado/Sociedade. Promover a Segurança Alimentar e Nutricional (SAN) passou a ser uma responsabilidade do Estado mediante a implementação de políticas públicas capazes de garantir a realização do DHAAS. A escolha política de identificar a alimentação no rol dos direitos humanos e, essa abordagem como objeto da Política Nacional de Segurança Alimentar e Nutricional (PNSAN), confere ao tema uma perspectiva de equidade, a partir das singularidades dos sujeitos ${ }^{[1]}$.

Este ensaio se propõe a resgatar alguns fatos e ponderações do processo de construção e significação dos conceitos de Alimentação Adequada e Saudável (AAS) durante o processo político institucional e participativo de formulação de políticas públicas de 2006 a 2015, evidenciando suas contradições e destacando os momentos onde a comida e seus aspectos simbólicos, passaram a influenciar a percepção e as decisões relacionadas aos programas e políticas de SAN/DHAAS. Meu lugar de fala, se deu, em muitos momentos, a partir dos fóruns aqui destacados. Sendo assim, proponho-me a narrar e analisar fatos históricos que vivenciei e me são, ainda hoje familiares. Na medida que deles faço parte, me incluo na análise como sujeito e pesquisador, não ignorando a participação e memória individual. De acordo com Versiani ${ }^{[2]}$, o sujeito não é estável e unívoco pois a subjetividade é construída dialogicamente em processos interpessoais.

O marco legal institucional da SAN tornouse realidade a partir da aprovação da Lei Orgânica de Segurança Alimentar e Nutricional (LOSAN) [3], em setembro de 2006, com o objetivo de assegurar a alimentação como um direito humano, por meio da criação do Sistema Nacional de Segurança Alimentar e Nutricional - SISAN, prevendo ações baseadas nos princípios da universalidade e da equidade do acesso à alimentação adequada, com participação social na formulação, execução, acompanhamento, monitoramento e controle das políticas e dos planos de ação, em todas as esferas de governo, e a transparência dos programas, das ações e dos recursos públicos e privados e dos critérios para sua concessão.

Por serem inerentes ao ser humano, os direitos humanos encontram o seu fundamento na noção de dignidade da pessoa humana. Os direitos humanos podem ser conceituados como prerrogativas inerentes à dignidade humana que são reconhecidas na ordem constitucional dos Estados ${ }^{[4]}$.

Os direitos humanos são universais, indivisíveis, inalienáveis, interdependentes e interrelacionados, tendo como base princípios que devem nortear a sua realização: a participação e a inclusão, a equidade e a não-discriminação, a responsabilização e o Estado de Direito ${ }^{[1]}$.

Em 2010, foi publicada a PNSAN que definiu as diretrizes e o Plano de Segurança Alimentar e Nutricional (PLANSAN), configurando, junto com a LOSAN, a tríade jurídico legal da SAN no Brasil. O desafio do arranjo institucional tornouse a articulação da Política, Plano e Sistema de SAN (SISAN) com a viabilização de um sistema capaz de promover a gestão única de ações articuladas em nível intersetorial, nos âmbitos das esferas federal, estadual e municipal do Estado e sob a permanente participação da sociedade civil nas etapas de planejamento, gestão, monitoramento e avaliação através dos Conselhos e Conferências de SAN[5].

O local que acolheu e legitimou as reflexões e debates sobre temas estratégicos para a SAN, foi o Conselho Nacional de SAN (CONSEA) que, em suas Comissões Permanentes e Grupos de Trabalho, 
concedeu espaço para divergências, diálogos, resolução de conflitos e formação de consensos. Com um caráter intersetorial, se consolidou, reunindo setores que trabalham com a "comida de verdade", em todas as etapas do processo: desde a escolha da semente (origem), técnicas de produção sustentáveis, aproveitamento integral dos alimentos e reciclagem (meio ambiente) até o consumo, incluindo desde os aspectos socioantropológicos e culturais, até a utilização biológica e seus riscos à saúde.

Incorporando essas perspectivas, avançouse na proposição de politicas públicas para o enfrentamento da Insegurança Alimentar e Nutricional (IAN), no tencionamento teórico-crítico ao sistema agroalimentar hegemônico e no apoio a rede de Conselhos estaduais e municipais.

Junto a estas inciativas, foi formado um Grupo de Trabalho (GT) para discutir o conceito de "alimentação saudável". O GT interdisciplinar envolveu os campos da saúde, agrárias, agroecologia e áreas correlatas com representações de movimentos sociais, pesquisadores, professores universitários, gestores, consultores e assessores técnicos de Ministérios, membros de Organismos Internacionais e Organizações Não Governamentais (ONGS), relacionadas ao tema.

A compreensão de que alimentação é uma das dimensões fundantes das culturas se destaca nos processos e narrativas de atores, pesquisadores, gestores e documentos institucionais relacionados segurança alimentar e nutricional[6,7,8]. Nesta perspectiva, o termo culturas alimentares passa a se revestir de duplo sentido, pois as comidas carregam em si marcadores culturais. As culturas alimentares são teias de signos, símbolos, práticas e rituais que expressam valores e significados sociais, coletivos, ainda que realizados individualmente. Os efeitos e repercussões das culturas alimentares difundem-se e misturam-se dinâmica e permanentemente, gerando novos processos e leituras sociais. Tudo o que as pessoas são, pensam e fazem, seus atos e as suas consequências, são sempre significantes de uma prática coletiva. Por isso, o comportamento social não pode ser reduzido a uma análise do comportamento individual[ ${ }^{[9]}$. A alimentação é uma expressão dos arranjos culturais que dialogam com essa complexidade, onde diferentes símbolos, gramáticas e significados individuais compõem a dinâmica sociocultural, histórica e diversa.

O Relatório Final desse GT, espelha as reflexões sobre a relação entre alimentação e cultura:

“A promoção da alimentação adequada e saudável deve permitir e estimular a junção dos componentes, biológicos, simbólicos e culturais que estão conjugados na matriz de compreensão do alimento e de sua alimentação pelos seres humanos. Este princípio agrega a visão que a produção dos alimentos expressa à cultura dos povos, de forma ambientalmente sustentável, pela valorização de seu patrimônio alimentar através da produção, comercialização e abastecimento a partir da valorização da diversidade cultural, tendo a ancestralidade como expressão da bagagem cultural de raças, etnias gêneros e da sociedade de forma emancipadora. As formas de compreensão dos sistemas classificatórios de alimentos do ser humano que expressam: sua relação com sua natureza intrínseca, a sua experiência com a natureza e sua expressão biológica e simbólicocultural. O conceito de comida deve ser estimulado como expressão de identidade social, como diálogo na promoção da alimentação adequada e saudável em ações e programas de promoção da saúde e produção de alimentos" $[10]$.

O conceito apresenta dimensões importantes para os desafios contemporâneos do comer em sociedade e nos permite analisar o significado da comida e suas expressões simbólicas, no âmbito da alimentação saudável e adequada.

A narrativa conceitual se estrutura a partir de uma abordagem relacional dos enfoques: meio ambiente/natureza/alimento; saúde/biológico e comida/cultural/simbólico. A AAS é afirmada como uma abordagem complexa pois, sendo o simbólico um sistema de valores que determina a relação com a saúde e o meio ambiente, as origens (inter)culturais brasileiras passam a ser reconhecidas no campo da Segurança Alimentar e Nutricional. 
Chegar a esta conclusão, com certeza, é mais fácil do que compreender as dimensões que a sustentam e a configuram culturalmente. $\mathrm{O}$ que a comida e o simbólico acrescentam ao conceito de alimentação adequada e saudável? Provavelmente, a associação mais óbvia está na relação com os tabus e crenças alimentares, e de fato, pensar sobre este aspecto, pode ser um bom começo mas, o que precisa ser compreendido, não é a explicação objetiva sobre tabus e crenças. O que precisamos incorporar a esta abordagem, é a compreensão sobre o subjetivo e as redes de significados que suportam as crenças/tabus na configuração das culturas alimentares. Do ponto de vista antropológico, é importante aceitar que são as formas culturais de comer que condicionam a nossa necessidade biológica fazê-lo. São estas redes de significações que circunscrevem o ato de comer, como a maneira "certa" ou "errada" de fazê-lo.

Assim, a dimensão simbólica se revela quando compreendemos que o ato de comer, que poderia parecer simples e objetivo, é na verdade, um fenômeno complexo e subjetivo, pois não é exclusivamente biológico, nem tampouco totalmente social, e que une o biológico e o cultural de uma maneira tão indissolúvel que dificilmente será possível separá-los ${ }^{[11]}$.

Analisando também o conceito acima descrito, fica evidente que a relação alimento e comida é atravessada/compartilhada pelos dois aspectos, o biológico e cultural. A referência a “...matriz de compreensão dos alimentos e (...) alimentação pelos seres humanos" e "As formas de classificação dos sistemas classificatórios de alimentos..." explicitam o limite e/ou a intersecção entre "ser ou não ser" comestível. A comida é a tradução cultural do alimento que passa a ser comestível, expressando as identidades e subjetividades dos diferentes sistemas culinários ${ }^{[11,12]}$. Da Matta[13], pondera que os alimentos têm um caráter de universalidade e só a comida é que lhe particulariza pois, revela as identidades de quem o prepara. Adicionando o ser, fazer, estar e viver dos sujeitos às preparações e assim, as tornando singulares e carregando expressão simbólica.

Para Woortaman[14], a comida é uma construção ideológica com dimensões simbólicas que anuncia a escolha e a seleção de alimentos articulada a natureza, biologia e sociedade, constituindo-se como um habitus. Para Bourdieu[15], o habitus representa uma dimensão estruturante, como um sistema de reproduções duráveis e transportáveis que configuram, por exemplo, a cultura alimentar. As disposições da cultura alimentar geram representações sociais e configuram um capital social simbólico para as sociedades. A comida pode ser compreendida como uma expressão conceitual da vida cotidiana que transcende o ato de alimentar-se e indica a materialização da condição, identidade e diferenças sociais ${ }^{[9]}$.

Mintz define cultura como uma propriedade humana ímpar, baseada em uma forma simbólica, relacionada ao tempo, de comunicação e vida social. A qualidade cumulativa de interação humana, permitindo que as ideias, a tecnologia e a cultura material se organizem no interior dos grupos humanos. A alimentação é um dos marcadores dessas construções simbólicas e significantes. E a comida está inserida em um corpo substantivo de materiais culturais historicamente determinados ou derivados ${ }^{[16]}$.

$\mathrm{O}$ ato de alimentar-se transforma a alimentação em um rito, em um ato social ao redor da comida. Na gramática cultural, as comidas possuem historicidade e uma dinâmica própria fundada por conhecimentos antropológicos, que nem sempre alimentam, mas, podem estabelecer identidades sociais. Expressam funcionamento social e "estimulam" relações sociais, como categoria do cotidiano, estando envoltas em significados, expressando relações e atuando como estruturantes da organização social[9].

Estas percepções nos chamam a analisar mais cuidadosamente os aspectos subjetivos e simbólicos da alimentação. Se a comida, pode ser compreendida como uma expressão cultural e conceitual, do mundo e da vida cotidiana, que capital simbólico estamos expressando com as práticas alimentares contemporâneas? Qual expressão conceitual da vida cotidiana está implícita nas maneiras de comer da atualidade? Os sistemas alimentares e culinários expressam as dimensões simbólicas e sociais das sociedades ${ }^{[9,16]}$.

O GT concluiu que o conceito que "Alimentação Saudável" deveria ser ampliado para "Adequada e Saudável" a fim de acolher sua 
complexidade e abrangência. A alimentação adequada e saudável (AAS), não se limita ao momento de ingestão de nutrientes, pois:

"é a realização de um direito humano básico, com a garantia ao acesso permanente e regular, de forma socialmente justa, a uma prática alimentar adequada aos aspectos biológicos e sociais dos indivíduos, de acordo com o ciclo de vida e as necessidades alimentares especiais. Deve atender aos princípios da variedade, equilíbrio, moderação, prazer (sabor), às dimensões de gênero e etnia, e às formas de produção ambientalmente sustentáveis, livre de contaminantes físicos, químicos, biológicos, de organismos geneticamente modificado e pautada no referencial tradicional local identificado pelos seus povos e comunidades"[10].

Esse conceito foi incorporado à alguns documentos institucionais como a Política Nacional de Alimentação e Nutrição (PNAN), ainda que com restrições no que tange aos agrotóxicos e transgênicos. $O$ conceito foi um parâmetro muito importante, pois passou a orientar a concepção de alimentação que a Constituição Federal brasileira, em seu capítulo 6 , afirma ser um direito de cidadania.

Convém esclarecer que a nomenclatura descrita na LOSAN refere-se ao termo Direito Humano à Alimentação Adequada (DHAA), proveniente do contexto internacional[1]. $O$ debate realizado entre sociedade e Estado no âmbito do CONSEA e das Conferências de SAN, incorporou o termo saudável ao contexto do DHAA. Este ensaio por concordância teórica e política, apresenta parte do processo desta legitimação e, por isso fará referência ao conceito DHAAS.

O DHAA é um direito inerente a todas as pessoas de ter acesso regular, permanente e irrestrito, quer diretamente ou por meio de aquisições financeiras, a alimentos seguros e saudáveis, em quantidade e qualidade adequadas e suficientes, correspondentes as tradições culturais do seu povo e que garantam uma vida livre do medo, digna e plena nas dimensões física e mental, individual e coletiva ${ }^{[1]}$.
Já o DHAAS, considera os mesmos pressupostos jurídico - legais do DHAA, qualificando que tipo de alimentação deve ser garantida, ou seja, evidencia aspectos éticos, humanos, culturais e simbólicos da dimensão do saudável como parte também das obrigações do Estado para a garantia da SAN $[17,18]$.

Vale destacar que no campo internacional, o conceito do DHAA está em revisão e vem sendo proposto uma construção mais abrangente denominada Direito Humano à Alimentação e à Nutrição Adequadas (DHANA) ${ }^{[19]}$. O Brasil, é vanguarda na concepção e prática da abordagem sobre direitos humanos e alimentação e nutrição e políticas públicas no contexto internacional.

No âmbito das políticas públicas, outros materiais instrucionais, orientadores no contexto da agenda de saúde e SAN, nos estados e municípios brasileiros, por meio do Sistema Único de Saúde (SUS) e SISAN, também incorporaram o conceito de AAS. Foram eles: o Guia Alimentar para a População Brasileira do Ministério da Saúde, de 2006 e de 2014 (ambos, progressivamente assumiram a necessidade de ressignificar a alimentação) e o Marco de Referência de Educação Alimentar e Nutricional para políticas Públicas, do Ministério do Desenvolvimento Social e Combate à Fome[20,17,21].

É interessante registar que durante o processo de construção do primeiro Guia Alimentar para a população brasileira ${ }^{[20]}$ o conceito de alimentação saudável já estava em discussão, como revela um trecho de um texto referenciado nos debates do SUS sobre o tema:

\footnotetext{
“Uma alimentação saudável, entendida enquanto um direito humano compreende um padrão alimentar adequado as necessidades biológicas e sociais dos indivíduos de acordo com as fases do curso da vida. balanceada, que tem por característica três princípios: i) variedade, comer diferentes tipos de alimentos pertencentes aos diversos grupos; ii) moderação, não exagerar nas quantidades de alimentos ingeridas e iii) equilíbrio, consumir alimentos variados, respeitando a quantidade de porções recomendadas para cada grupo de alimentos. Além disso, uma alimentação
} 
saudável deve ser baseada em práticas alimentares assumindo os significados socioculturais dos alimentos como fundamento básico conceitual. Uma alimentação saudável é adequada quando também compreende aspectos relativos a percepção dos sujeitos sobre os modos de vida adequados, ou seja, quando alcança as expectativas identificadas pela sociedade como ideais. Neste sentido as dimensões de variedade, quantidade, qualidade e harmonia se associam aos padrões culturais, regionais, antropológicos e sociais das populações"[22].

O Guia Alimentar para a população brasileira ${ }^{[17]}$ atual, expressou o acúmulo do processo, histórica e politicamente determinados, reconhecendo as tensões com os setores econômicos que representam os interesses do sistema agroalimentar hegemônico e incorporando a importância dos aspectos culturais e de sustentabilidade ambiental relacionados ao sistema alimentar para AAS.

Além disso, a formulação do conceito, no espaço do CONSEA, gerou a aproximação com setores fundamentais para a construção da intersetorialidade e para a compreensão dos múltiplos significados da alimentação. Assim, a alimentação escolar e a agricultura familiar, tornaram-se expressão dessa possibilidade. Um conjunto de normativos legais foram responsáveis por aprimorar o Programa Nacional de Alimentação Escolar (PNAE). A Lei no 11.947, de 16 de junho de 2009, determinou que no mínimo $30 \%$ do valor repassado a estados, municípios e Distrito Federal pelo Fundo Nacional de Desenvolvimento da Educação (FNDE) para o PNAE, deve ser utilizado na compra de gêneros alimentícios diretamente da agricultura familiar, priorizando-se os assentamentos da reforma agrária, as comunidades tradicionais indígenas e as comunidades quilombolas. A aquisição dos produtos da Agricultura Familiar dispensa o procedimento licitatório e pode ser realizado por meio de chamada pública, desburocratizando o processo ${ }^{[23]}$.

Iniciativas provocadas por estas reflexões, como convidar os sujeitos, tanto formuladores quanto gestores e beneficiários do PNAE, a pensar sobre alimentação, a partir do planejamento do cardápio e estabelecimento de relações com os agricultores e produtores dos alimentos, torna-se um estímulo a revisitar memórias culinárias, histórias familiares, regionais e culturais na relação com a terra e os territórios. Exercícios assim, alertam sobre os limites que os processos burocráticos podem impor à promoção da AAS, em relação a elaboração de comidas, que sejam simbolicamente reconhecidas e socialmente aceitas.

Por isso, incluir os agricultores e agricultoras, professores e professoras, pais, merendeiras e estudantes (comunidade) como coparticipantes do processo, auxilia no resgate e inserção de atitudes, significados e práticas alimentares culturalmente identificadas na preparação da alimentação escolar. Assim, o alimento, antes aleatoriamente recebido pela escola, passa a revelar seu potencial simbólico de celebração, comensalidade e outros aspectos culturais e históricos da comunidade. Este movimento tem colaborado para a ressignificação das práticas de alimentação e nutrição em saúde coletiva.

A alimentação e a comida constituem-se em categorias, politicamente imbricadas, mas socialmente distintas e, no cenário dos programas e políticas públicas de SAN/DHAAS, não é diferente. Incorporar o conceito e seus desafios, na construção das políticas públicas, ainda que insuficiente para dar visibilidade e apresentar a complexidade dos aspectos antropológicos e da ordem cultural na determinação das escolhas alimentares, parece ter iluminado uma parte do percurso no que tange ao reconhecimento sobre a origem dos alimentos e sua importância como identidade social e cultural.

Essas compreensões evidenciam a importância de considerar os territórios, os sujeitos, as dinâmicas sociais e as singularidades regionais dos distintos povos e comunidades, incorporando a "diferença", por meio do pressuposto da equidade como estruturante para o alcance dos objetivos das políticas de SAN/DHHAs.

Contudo, apesar da compreensão do "saudável" e "adequada", ter aprofundado uma reflexão, o seu significado social é polissêmico e culturalmente determinado. No campo hegemônico do setor saúde, ainda há tensões frente o paradigma 
biomédico. Cabe ao setor saúde a expectativa e a "responsabilidade" de um cuidado institucionalmente voltado para o adoecimento e tratamento de sinais e sintomas, que na prática monitoram e "vigiam" resultados e parâmetros bioquímicos, clínicos e nutricionais como: índices, taxas, medicamentos, exames, procedimentos, etc.

Apesar das políticas, programas e projetos em SAN e alimentação e nutrição em saúde coletiva promoverem uma abordagem intersetorial, é nas políticas setoriais que as práticas, ações e cuidados ocorrem. Atualmente, muitos profissionais de saúde e SAN, perante a dificuldade de enfrentamento da problemática da IAN, compreendem que abordagens relacionadas ao "comer em sociedade" precisam se organizar, a partir do reconhecimento socioantropológico das práticas alimentares locais, levando em conta as redes sociais que suportam e constituem os sistemas culinários e suas características históricas. A imposição de modelos de assistência biologicistas tem sido incapazes de dialogar com as necessidades em saúde tensionado a autonomia dos saberes, a soberania alimentar e as práticas culturalmente construídas pelas sociedades.

Suprir as necessidades nutricionais e "atender aos princípios biológicos da variedade, equilíbrio, moderação, prazer (sabor)", só é possível a partir de um diálogo ou linguagem intercultural que reconheça as dimensões subjetivas das escolhas alimentares, vivenciadas nos processos históricos, culturais e antropológicos dos sujeitos ${ }^{[10]}$.

As escolhas alimentares são motivadas por vários fatores e apesar das necessidades biológicas, como questão central de sobrevivência da espécie, os critérios que nos permitem identificar as possibilidades alimentares são economicamente definidos, pois dependem das condições materiais disponíveis ${ }^{[24]}$.

Outra questão relevante para a reflexão se refere a percepção subjetiva das sensações relacionadas ao comer. Cruz ${ }^{[25]}$, descreve que a fome e o apetite são impulsos alimentares, inerentes a todos seres humanos. Muito embora possam expressar-se de maneira diferente, movimentam os corpos (humanos), por meio de desejos e vontades, para o alcance da sua satisfação. A fome e o apetite são dimensões fisiológicas do instinto alimentar que é inato, subjetivo, não racional e permanente. Ambos, dimensões constituintes da espécie humana.

O apetite se diferencia da fome, principalmente, por seu caráter seletivo e nominável. É um fator psico-fisiológico orgânico, motivado pelo desejo especifico de um alimento na busca de prazer. É um estado consciente caracterizado pelo desejo de comer, condicionado por uma experiência anterior e provocado por uma memória alimentar (gosto) de uma comida (re)conhecida. A seletividade do apetite atribui a ele uma perspectiva diversa, ou seja, o que satisfaz a uma pessoa pode não satisfazer a outra, expressando as subjetividades e singularidades sociais. Apetite é um componente biológico que expressa conexões biopsicossociais, revelando valores culturais ${ }^{[25]}$.

O termo fome, ainda que relacionado ao contexto da pobreza, privação e exclusão social não desassocia-se do desejo, vontade e impulso. A fome é uma expressão do impulso alimentar, assim como o apetite. Ambos são necessidades humanas, psicológicas, biológicas e sociais, ou seja, formam um conjunto de sentidos e expressões do impulso alimentar que precisam se contemplados na totalidade das políticas, projetos, programas e ações sociais para o pleno desenvolvimento das necessidades humanas.

Estratégias, programas e ações políticas focadas na erradicação da fome (ausência de alimentos) que desconsideram o apetite como parte integrante do impulso alimentar, ferem a dignidade humana, pois não levam em consideração aspectos relativos à cultura alimentar dos distintos povos e comunidades que constituem as sociedades. A seletividade do apetite requer uma memória alimentar que está presente nos traços socioantropológicos e culturais, cultivados e vivenciados por meio dos valores, atitudes, práticas, símbolos, costumes e patrimônios alimentares.

A fome, sob a perspectiva social, também pode ser analisada como um conjunto de ameaças, barreiras ou dificuldades para garantir necessidades humanas, de maneira equitativa. Para além da abordagem sobre escassez e falta de alimentos, a insegurança coletiva de acesso à AAS ou o conjunto de ameaças e violações para o cumprimento do 
DHAAS pode revelar outra dimensão da fome: a ético - política.

A AAS, pressupõe que escolhas alimentares, o que se come e como se come, expressam a complexidade do ato alimentar pois são definidos socialmente, ainda que, de acordo vontades e desejos individuais. Esta seleção depende, essencialmente da relação entre o mercado e a criação de subjetividadades sociais no diálogo com a cultura, ou seja, da ordem econômica financeira com os sistemas culinários culturais que ancoram os valores, práticas, atitudes, significados e gostos sociais. O acesso, a oferta e distribuição de alimentos é fortemente influenciada pelos sistemas de produção e distribuição, assim como as formas possíveis de preparação e consumo dos alimentos.

Assim, analisando a complexidade do sistema alimentar, há dimensões de violação do DHAAS em todos os segmentos sociais pois, para além do acesso físico e financeiro, outras dimensões da lógica de produção de alimentos e do sistema alimentar, adulteram a qualidade dos alimentos e promovem IAN na sociedade. Há risco de contaminação de alimentos por produtos tóxicos (agrotóxicos, aditivos, antibióticos, etc.), há limitação de oferta de alimentos saudáveis, ambientalmente sustentáveis e culturalmente identificados, ao mesmo tempo em que há oferta demasiada de alimentos ultraprocessados nos estabelecimentos que comercializam alimentos, há elevação de casos de transtornos alimentares entre jovens, há abandono social de idosos com quadros de desnutrição e doenças carenciais ou degenerativas importantes, há efeitos perversos na saúde da mulher em função da objetificação histórico - política de seus corpos na acumulação capitalista, há sintomas sociais incômodos provocados pela invasão de publicidade infantil de alimentos na TV, mídias e redes sociais. Imposições econômicas geram situações de violação de direitos, constrangimentos éticos e iniquidade alimentar que precisam ser reconhecidas na determinação social da IAN.

Todos estes processos repercutem na compreensão e identidade cultural da comida enquanto um patrimônio cultural, violando o DHAAS e ameaçando a SAN localmente referenciadas. O modo de comer moderno tem muitas contradições inerentes da ordem econômica social vigente.
Em 2015, na continuidade da reflexão sobre a alimentação adequada e saudável no campo das políticas públicas de alimentação e nutrição, o termo "comida de verdade" é aprovado como lema da V Conferência Nacional de Segurança Alimentar e Nutricional, explicitando no Manifesto aprovado em sua plenária final: Manifesto sobre Comida de Verdade no Campo e na Cidade, por Direitos e Soberania Alimentar, os aspectos simbólicos e culturais da alimentação[26].

Em um cenário de insegurança alimentar e nutricional permanente, apropriar-se do saber fazer culinário, ressignificar as práticas culinárias colaborativas entre todos os membros do espaço doméstico, conhecer e consumir alimentos in natura e Plantas Alimentícias Não Convencionais (PANCS), para além de uma estratégia de comensalidade, passa a ser uma estratégia de vida, pois pode contribuir para a promoção da alimentação adequada e saudável.

A recente extinção do Conselho Nacional de Segurança Alimentar e Nutricional em 01 de janeiro de 2019, pelo presidente Jair Bolsonaro, por meio da medida provisória 870 de 01 de janeiro de 2019, configura-se em uma perda substancial para o contexto aqui debatido. O CONSEA, constituiu-se com um espaço legítimo de participação social para monitoramento e avaliação de políticas e programas, defesa de direitos e, acima de tudo, reflexão e construção de novas estratégias de políticas, programas, projetos tanto no âmbito do executivo, quanto do poder judiciário e o legislativo. Sua extinção arbitrária é um retrocesso social. O CONSEA é um espaço de vigilância para que o Estado não deixe de cumprir seu dever constitucional para a garantia da SAN, é a voz da sociedade nos processos decisórios relacionados ao direito à alimentação adequada e saudável digna, justa e consciente, no Brasil.

A sociedade Brasileira, reagiu ao ato e em 27 de janeiro de 2019, promoveu um ato político denominado "Banquetaço" em 43 cidades, simultaneamente. A proposta configurou-se em atividades, artísticas, culturais e políticas ao redor da importância do comer em sociedade, tendo como eixo central a distribuição de refeições boas, limpas e justas preparadas com alimentos provenientes da agricultura familiar e PANCs, das redes de produção 
agroecológicas, movimentos sociais, cooperativas e da Rede de Comunidade Sustentando a Agricultura (CSA) que se organiza a partir de grupos de consumo consciente co-financiando a produção de forma colaborativa e participatival[27.

A mobilização social nacional teve êxito na articulação política realizada junto ao Congresso Nacional, acarretando à aprovação de emendas que anularam sua extinção, contudo o presidente, ignorando a vontade popular, manteve o veto e hoje, a rede dos CONSEAS estaduais e municipais, que estão ativos, se mantém fragilizada e sem o apoio do CONSEA Nacional.

Em que pese o desmonte do Estado na proposição das políticas públicas relacionadas às garantias fundamentais dos cidadão e cidadãs brasileiras, às mobilizações sociais precisam prosseguir resistindo, tencionando, denunciando e propondo alternativas para qualificação, expansão e humanização de programas e projetos voltados para a garantia da SAN e a afirmação de direitos sociais.

Além disso, criar fissuras no mercado e modo de produção capitalista, com outras formas de produção, distribuição, comercialização, consumo e/ou compartilhamento de alimentos, podem ser caminhos capazes de empoderar novos atores, permitir outras experiências, vivenciar modos de viver menos desiguais, mais conscientes e contra hegemônicos à lógica do sistema agroalimentar vigente. Esses novos arranjos de convívio, diálogos e trocas, que reposicionam papel da alimentação na vida em sociedade, podem ser potentes gatilhos para a ressignificação de valores simbólicos, atitudes e práticas culturais, ameaçadas pela lógica do alimentomercadoria.

As dimensões socioculturais da alimentação, unidas a dimensão subjetiva, integram os sujeitos com sua própria história e as dinâmicas da sociedade em seu tempo, tendo sido responsáveis pela própria origem da organização da vida em sociedade. A comida e seus aspectos simbólicos são expressões de significado da alimentação.

Compreender a importância da comida e do simbólico para a implementação de políticas para o cumprimento do DHHAS, é um desafio a ser construído de forma participativa e demanda um urgente debate epistemológico que incorpore a premissa interdisciplinar, complexa, interseccional e intercultural da alimentação com os campos do saber que a configuram.

\section{REFERÊNCIAS}

[1] Ação Brasileira para Nutrição e Direitos Humanos ABRANDH. O Direito Humano à Alimentação e o Sistema Nacional de Segurança Alimentar e Nutricional. Brasília: ABRANDH; 2013.

[2] Versiani DB. Autoetnografia: uma alternativa conceitual. Letras de Hoje. 2002; 4:57-72.

[3] Brasil. Lei no 11.346, de 15 de setembro de 2006. Lei Orgânica de Segurança Alimentar e Nutricional. Cria o Sistema Nacional de Segurança Alimentar e Nutricional SISAN com vistas a assegurar o direito humano à alimentação adequada e dá outras providências. Diário Oficial da União. 18 set. 2006.

[4] Chimenti RC, Capez F, Rosa MFE. Curso de Direito Constitucional. 5. ed. São Paulo: Saraiva; 2008.

[5] Brasil. Decreto no 7.272, de 25 de agosto de 2010. Regulamenta a Lei no 11.346, de 15 de setembro de 2006, que cria o Sistema Nacional de Segurança Alimentar e Nutricional - SISAN com vistas a assegurar o direito humano à alimentação adequada, institui a Política Nacional de Segurança Alimentar e Nutricional - PNSAN, estabelece os parâmetros para a elaboração do Plano Nacional de Segurança Alimentar e Nutricional, e dá outras providências. Diário Oficial da União. 26 out. 2010.

[6] Conselho Nacional de Segurança Alimentar e Nutricional. Relatório Final: 3a Conferência Nacional de Segurança Alimentar e Nutricional. Brasília: CONSEA; 2007.

[7] Conselho Nacional de Segurança Alimentar e Nutricional. Relatório Final: 4a Conferência Nacional de Segurança Alimentar e Nutricional. Brasília: CONSEA; 2011.

[8] Conselho Nacional de Segurança Alimentar e Nutricional. Relatório Final: 5a Conferência Nacional de Segurança Alimentar. Brasília: CONSEA; 2015.

[9] Freitas MCSF, Oliveira D. Narrativas sobre o comer no mundo da vida. Salvador: EDUFBA; 2013. 
[10] Conselho Nacional de Segurança Alimentar e Nutricional. Relatório Final. GT Alimentação Adequada e Saudável. Brasília: CONSEA; 2007.

[11] Aguirre P. Ricos fracos e gordos pobres: a alimentação em crise: desafios para todos. Buenos Aires: Ed. Capital Intelectual; 2004.

[12] Fischler C. L'(H)omnivore. Barcelona: Anagrama; 1995.

[13] Da Matta R. O que faz do Brasil, Brasil. Rio de Janeiro: Rocco; 1986.

[14] Woortamann K. Hábitos e Tabus Alimentares em populações de baixa renda. Brasília: Departamento de Antropologia da UnB; 1978.

[15] Bourdieu P. O poder simbólico. Lisboa: Difusão Editorial; 1980.

[16] Mintz SW. Cultura: uma visão antropológica. Tempo. 2010; 28: 223-237.

[17] Brasil. Ministério da Saúde. Guia Alimentar para a população brasileira. Brasília: Ministério da Saúde; 2014.

[18] Brasil. Ministério do Desenvolvimento Social e Combate à Fome. Caderno Metodológico para Multiplicadores em SAN/DHAAS. Brasília: MDS; 2016.

[19] Santarelli M, Burity V. Da democratização ao golpe: avanços e retrocessos na garantia do direito humano à alimentação e à nutrição adequadas no Brasil. Brasília: FIAN Brasil; 2017.

[20] Brasil. Ministério da Saúde. Guia Alimentar para a população brasileira. Brasília: Ministério da Saúde; 2006.

[21] Brasil. Ministério do Desenvolvimento Social e Combate à Fome. Marco de Referência de Educação Alimentar e Nutricional para Políticas Públicas. Brasília: MDS; 2012.

[22] Pinheiro ARO, Recine E, Carvalho MF. O que é uma alimentação saudável: considerações sobre o conceito, princípios e características: uma abordagem ampliada. Brasília: Ministério da Saúde; 2005.

[23] Brasil. Fundo Nacional de Desenvolvimento da Educação - FNDE. Lei no 11.947, de 16 de junho de 2009. Dispõe sobre o atendimento da alimentação escolar e do
Programa Dinheiro Direto na Escola. Diário Oficial da União. 17 jun. 2009. Seção 1, p. 2.

[24] Harris M. Bueno para Comer. Madrid: Alianza Editorial; 2016.

[25] Cruz CJ. Alimentação e Cultura: antropologia da conduta alimentar. Navarra: EUNSA; 1991.

[26] Conselho Nacional de Segurança Alimentar e Nutricional. Manifesto da 5a Conferência Nacional de Segurança Alimentar e Nutricional à Sociedade Brasileira sobre Comida de Verdade no Campo e na Cidade, por Direitos e Soberania Alimentar. V Conferência Nacional de Segurança Alimentar e Nutricional: Relatório Final. Brasília: CONSEA; 2015.

[27] Azevedo E, Doria CA. Banquetaço: ativismo alimentar e a construção de novas formas de expressão política. Le Monde Diplomatique [internet]. 2019 [acesso em 16 jun 2020]. Disponível em: https:/ / diplomatique.org.br/banquetaco-ativismoalimentar 